\title{
Experimental-Based Optimization of Injection Molding Process Parameters for Short Product Cycle Time
}

\author{
Saad M. S. Mukras $\mathbb{D}$ \\ Department of Mechanical Engineering, College of Engineering, Qassim University, Buraydah, Qassim, Saudi Arabia \\ Correspondence should be addressed to Saad M. S. Mukras; mukras@qec.edu.sa
}

Received 31 December 2019; Accepted 13 February 2020; Published 11 March 2020

Academic Editor: Gyorgy Szekely

Copyright ( 2020 Saad M. S. Mukras. This is an open access article distributed under the Creative Commons Attribution License, which permits unrestricted use, distribution, and reproduction in any medium, provided the original work is properly cited.

\begin{abstract}
This paper presents a framework for optimizing injection molding process parameters for minimum product cycle time subjected to constraints on the product defects. Two product defects, namely, volumetric shrinkage and warpage, as well as seven process parameters including injection speed, injection pressure, cooling time, packing pressure, mold temperature, packing time, and melt temperature, were considered. Injection molding experiments were conducted on specifically chosen test points and results were used to compute the volumetric shrinkage and warpage (at each test point). Thereafter, three relationships between the product cycle time (one relationship), the two product defects (two relationships), and the injection molding parameters were constructed using the kriging technique. An optimization problem to minimize the product cycle time (described by the first relationship) subject to constraints on the product defects (described by the latter two relationships) was then formulated. A combination set of points between the lower and upper extreme values of acceptable product defect was generated to serve as constraints for the two product defects. The optimization problem was then solved using the Fmincon function, available in the Matlab optimization toolbox. A plot of the optimization results revealed an appreciable tradeoff between the cycle time and the two product defects. To validate the optimization, an additional injection molding experiment was conducted for one of the optimization results. Results from the additional experiment showed reasonably close agreement with simulation optimization results differing in the cycle time, the warpage and volumetric shrinkage by $6.7 \%, 3.2 \%$, and $8 \%$, respectively.
\end{abstract}

\section{Introduction}

Injection molding is undoubtedly among the most important industrial plastic processing techniques. It has been estimated that the process consumes approximately $32 \%$ [1] of all plastics. The process is widely used in the mass production of both commercial and consumer products. Its immense popularity is due to a number of factors including its reliability and its ability to produce complex shape in a single step with superb tolerance among others.

The injection molding process is achieved using an injection molding unit. A schematic of a typical injection molding unit is shown in Figure 1. The process is an unvarying, repetitive process that involves feeding plastic (pellets) to the barrel via a hopper, melting of plastic using heaters in a barrel, mixing the plastic using a rotating and reciprocating screw, injecting the molten plastic into a mold cavity, packing the molten plastic within the mold cavity, cooling of the molten plastic (in the mold cavity), and thereafter ejection of the solidified plastic part. The process is, thus, generally divided into 3 or 4 phase [2-5] which include filling, packing, cooling, and ejection. These phases determine the cycle time of the process, which is an important factor during production as it is directly linked to the cost of production. It can, therefore, be argued that reducing the cycle time (even seconds) within any of these phases will lead to time and cost-savings in the long run especially in the case of mass production.

A combination of various steps is usually taken to reduce the cycle time. This includes fine-tuning the injection molding unit to deliver proper injection pressures and speeds (which affects the filling time), designing the product to have minimum wall thickness (which affects the filling 


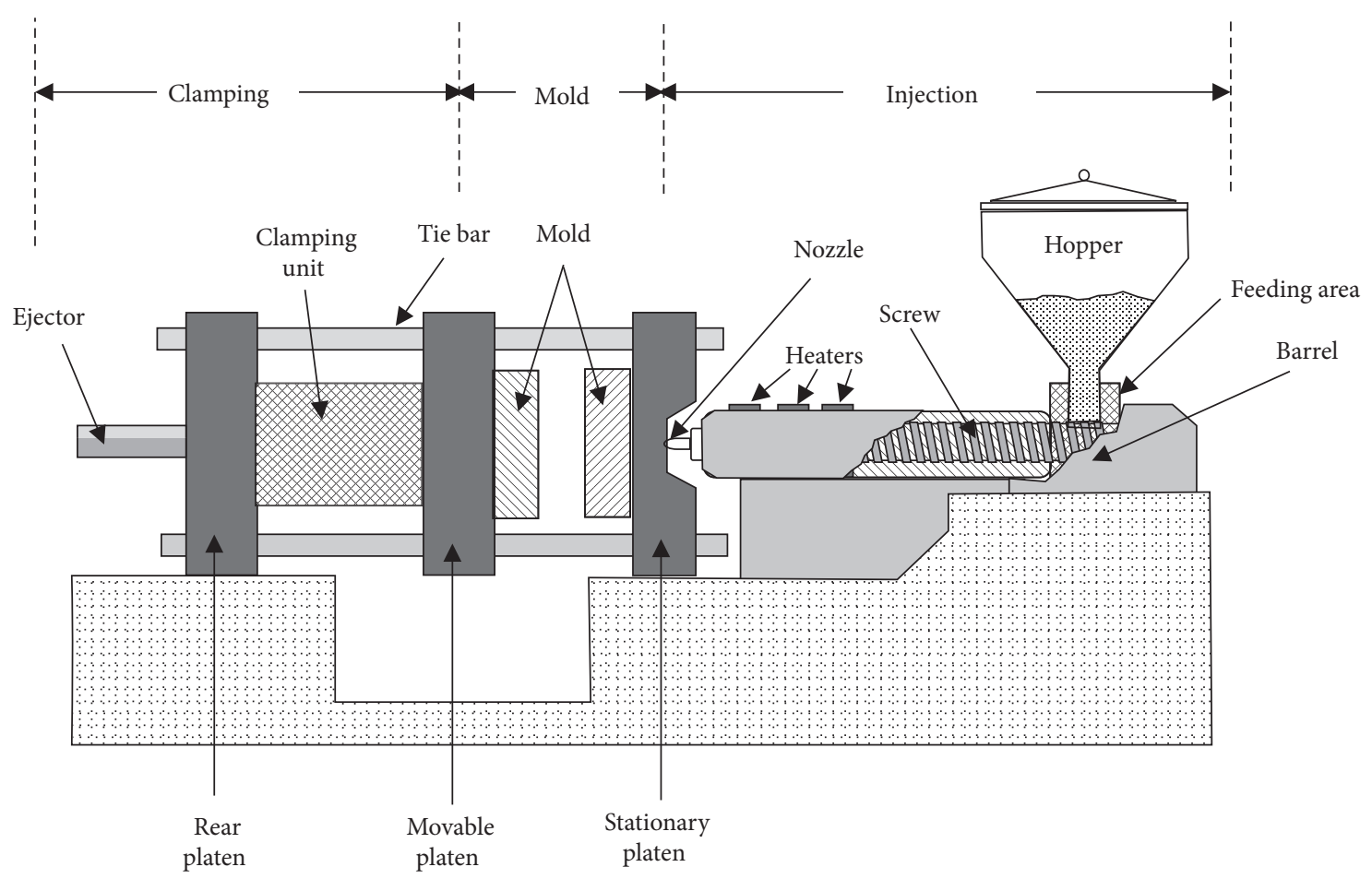

FIgURE 1: Detailed schematics of a typical injection molding unit.

time), making adjustments on the injection unit, such as mold opening and closing (which affects the ejection time), as well as other adjustments on the process parameters. Experienced plastic engineers who have gained insights on the process generally make these adjustments [6].

Of the four mentioned phases, the cooling phase takes up more than two-thirds of the cycle time $[4,7]$. It is also the most important phase in addition to productivity since the cooling has a significant effect on product quality. Inadequate cooling times will usually lead to defects on the product such as warpage and volumetric shrinkage. On the other hand, longer cooling times will generally lead to satisfactory product quality but result in low productivity (and consequently high production costs). This scenario has elicited research activities on ways to reduce the cooling time while ensuring acceptable product quality. Majority of these research activities have focused on conformal cooling channels within the molds to enhance and accelerate cooling [7-18]. In conformal cooling, the cooling channels are designed to conform to the shape of the mold cavity. It has been demonstrated that this technique enables the mold temperature to reach the operating temperature faster than in molds with standard cooling channels $[8,19]$.

There has also been some research into optimizing the process parameters for reduced cycle time. Zhao et al. [20] proposed a process parameter optimization procedure in which a surrogate model is used to approximate the expensive simulation that predicts the injection molding filling. The optimization was multiobjective and sought to lower the cavity pressure, minimize the temperature difference (ensuring uniformity in the melt temperature), and to minimize the cycle time by reducing the cooling time. In [21], Cheng et al. proposed a procedure to optimize injection molding process parameters through the formulation of a multiple objective optimization problem. The problem is formulated to minimize the product defect and the production cost (reduction of the cycle time) and to maximize the molding efficiency. The proposed procedure brought together the use of variable complexity methods, genetic algorithms, and neural networks, as well as injection molding simulations using Moldflow. In $[3,22]$, a procedure to optimize the injection molding process parameters for minimum warpage and cycle time is proposed. The authors confirm through numerical and experimental results the validity of the proposed procedure. In [23] Alvarado et al. proposed a multi- and many-objective optimization problem with 7 objectives including warpage, volumetric shrinkage, sink marks, Von Mises stress, shear stress, cycle time, and clamping force. Four process parameters, which included melt temperature, packing time packing pressure, and cooling time, were optimized.

In the literature, it is observed that the procedures proposed for process parameter optimization for reduced injection cycle time are primarily based on injection molding simulation tools instead of experiments. In these studies, results from injection molding simulations are used to construct relationships between the process parameters and quantities such as product defects and injection molding cycle time. It can, however, be argued that while simulations can produce useful results that can be the basis to advance to production, they generally have limitations as they may be unable to replicate all the physics involved in the process. Additionally, there may exist some conditions specific to the injection-molding machine that cannot be adequately captured in the simulations, and therefore experiments may be required to expose these conditions and or to validate the simulations. 
In this study, a procedure to optimize the process parameters for reduced cycle time is presented. The procedure involves constructing relationships between the process parameters and the product quality and another relationship between the process parameter and the cycle time. These relationships are similar to those developed in previous research except that they are developed using experimentbased design of experiments (DOE). This technique involved performing actual experiments (rather than numerical experiments) at specific points in the design space as determined using the selected DOE and thereafter using the data to construct the relationships. The use of experimental-based design of experiments technique is a generally accepted procedure and has been used in various disciplines such as in membranes [24], processing of food and bioproducts [25], photovoltaics [26], biotechnology [27], and analytical chemistry $[28,29]$. In this work, using this technique will mitigate computation costs while ensuring that all conditions specific to the injection-molding unit are captured in the analysis and, thus, leading to more accurate results of the optimized parameters.

\section{Injection Molding Experiments}

The injection molding process begins with feeding plastic pellets into the injection-molding unit (see Figure 1). The plastic pellets are then directed to the barrel of the injection units where they are mixed and heated, causing them to melt. The molten plastic is then subjected to pressure and injected into a mold cavity where it is packed (under pressure) and cooled, allowing it to solidify. The solidified plastic is then ejected from the unit as a finished product. The entire injection molding process requires the specification of certain processing parameters that will affect the product quality as well as the injection molding process cycle time.

In this study, experiments were conducted in an effort to arrive at the best combination of process parameters that would lead to the minimum cycle time while considering the extent of product defect (product quality). Two product defects were considered, namely, the warpage and volumetric shrinkage. Furthermore, seven process parameters, that have been shown to affect the product quality, are considered. These include the injection speed, injection pressure, cooling time, packing pressure, mold temperature, packing time, and melt temperature. The injection speed and injection pressure have been identified in [30,31], whereas the cooling time, packing pressure, mold temperature, packing time, and melt temperature have been identified in $[3,31-36]$ as having an effect on the product quality.

The experiments in this work were conducted on an injection molding unit known as the Arburg Allrounder $420 \mathrm{C}$ [37], and a simple mold with product dimensions depicted in Figure 2 was used. High-density polyethylene (M80064), produced by SABIC was used in the experiments. Some basic properties of the plastic, extracted from [38], are listed in Table 1.

In order to arrive at the best combination of the process parameter for minimum cycle time, a relationship between

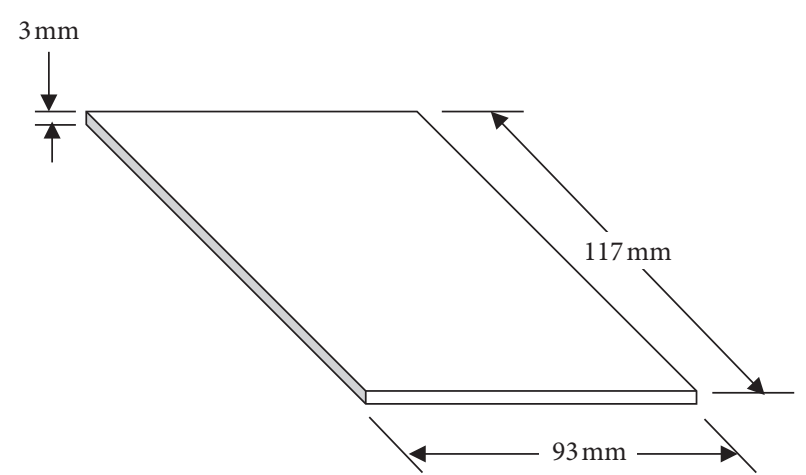

Figure 2: Geometry and dimensions of the injection-molded product used in the experiments.

TABle 1: Properties for HDPE M80064 series (produced by SABIC).

\begin{tabular}{lcc}
\hline Property & Unit & Value \\
\hline Stress at yield & $\mathrm{MPa}$ & 33 \\
Melt flow rate (at $190^{\circ} \mathrm{C}$ and $2.16 \mathrm{~kg}$ ) & $\mathrm{g} / 10 \mathrm{~min}$ & 8 \\
Density & $\mathrm{kg} / \mathrm{m}^{3}$ & 964 \\
\hline
\end{tabular}

the process parameter and the cycle time is to be constructed and optimized. The optimization is subjected to constraints on the extent of acceptable product defect which are represented by two other relationships between the product defects (warpage and volumetric shrinkage) and the process parameters.

2.1. Test Points for Injection Molding Experiments. The three relationships, mentioned previously, are constructed from data obtained through actual injection molding experiments performed at combination sets of the process parameters. These combination sets are selected through DOE in a manner that ensures that the design space is adequately covered. In this study, the central composite design (CCD) was adopted. The CCD is a factorial or fractional factorial design with center points which are augmented with star points that enhance the estimation of curvature. Depending on the location of the star point, the CCD can either be circumscribed, inscribed, or face-centered. In the CCD, the sample size is determined according to the following equation:

$$
2 f+2^{f-q}+1,
$$

where $f$ is the number of factors being considered (i.e., the process parameters in the current study) and $q$ refers to the fraction of the full factorial to be used. For a case where there are numerous factors (e.g., $f>5$ ), a full factorial design $(q=0)$ results in an enormous sample size. In such a case, it is advisable to use the fractional factorial design which utilizes only a fraction of the full factorial design without losing its main benefits. A detailed treatment of the $\mathrm{DOE}$ can be found in [39].

The complete design space for the seven process parameters is based on the upper and lower bounds of the 
parameters. The corresponding bounds of these parameters are listed in Table 2. The upper and lower bounds of the injection speed, cooling time, packing pressure, and packing times were suggested by experienced plastic technicians, whereas the bounds for the injection pressure, mold temperature, and melt temperature are based on the recommended ranges from the material producers [38]. For the current study, a half-fraction $(q=1)$ face-centered central composite design was used. Accordingly, for the seven parameters, 79 data points were generated.

2.2. Injection Molding Product Defect Quantification. Two relations relating the two defects (warpage and volumetric shrinkage) to the seven parameters need to be established. In order to achieve this, it is first necessary to quantify the defects. The defect quantification adopted in this work is described as follows.

2.2.1. Warpage Quantification. The warpage experienced in injection molding products can be defined as a deviation of the product geometry from the anticipated geometry. In this study, the warpage is defined as the sum of the maximum out-of-plane displacement of the product edges which can be expressed as

$$
W_{\text {sum }}=\sum y_{\text {maxi }_{i}, \quad i=1,2,3,4 .}
$$

In equation (2) $y_{\text {max }_{i}}$ refers to the maximum out-of-plane displacement along the four edges of the product. This definition has previously been used in [40].

2.2.2. Volumetric Shrinkage Quantification. The volumetric shrinkage can be estimated by determining the difference between the anticipated product volume ( $\left.V_{\text {anticipated }}\right)$ and the actual product volumes. The anticipated product volume is computed from the expected product dimensions (based on the diagram in Figure 2), whereas the actual product volume is computed from the known product density and measured mass. The volumetric shrinkage $V_{\text {shrinkage }}$ can, thus, be expressed as

$$
V_{\text {shrinkage }}=V_{\text {anticipated }}-\frac{m}{\rho} \text {. }
$$

This expression has also been previously used in [40].

2.3. Injection Molding Experiments. Injection molding experiments were performed on the 79 data points (previously generated). Pictures of samples of products from the experiments are shown in Figure 3. Figure 3(a) shows a product with severe volumetric shrinkage, and Figure $3(\mathrm{~b})$ shows a product with severe warpage. A product with minimal defects is shown in Figure 3(c).

Product defect, including warpage and volumetric shrinkage, was computed for the 79 products (using equations (2) and (3), respectively) and are reported in
TABLE 2: Lower and upper bounds for the test variables (bound for both the DOE and optimization).

\begin{tabular}{lccc}
\hline Test variables & Units & Lower bound & Upper bound \\
\hline Injection speed & $\mathrm{mm} / \mathrm{sec}$ & 15 & 60 \\
Injection pressure & $\mathrm{bar}$ & 450 & 800 \\
Cooling time & $\mathrm{sec}$ & 10 & 30 \\
Packing pressure & $\mathrm{bar}$ & 100 & 400 \\
Mold temperature & ${ }^{\circ} \mathrm{C}$ & 15 & 45 \\
Packing time & $\mathrm{sec}$ & 3 & 9 \\
Melt temperature & ${ }^{\circ} \mathrm{C}$ & 200 & 250 \\
\hline
\end{tabular}

Table 3. Also listed in Table 3 are the corresponding cycle times for each of the 79 products.

\section{Injection Molding Parameter Optimization}

The injection molding process parameters for reduced cycle time subjected to constraints on the product defect are to be determined through optimization. To achieve this, it is necessary to develop the relationship between the process parameters and the cycle time. It is also necessary to develop two other relationships between the two product defects and the process parameters. The former relationship can then be optimized subject to constraints on the defects (as described by the latter two relationships). A description of the development of the three relationships followed by the formulation of the optimization problem is presented in the following sections.

3.1. Kriging Model. A variety of models have previously been used to represent the relationship between the process parameters and the product defect. Some of these techniques include the artificial neural network [41-47], support vector regression [48], kriging [40, 49], and response surface method [50-52]. In this work, we adopt the kriging model to develop the relationship between the process parameters and the product defect and the relationship between the process parameters and the product cycle time.

Kriging is a regression interpolation technique developed by geologists in an attempt to predict the properties of minerals in a specified region based on knowledge of properties in other neighboring regions [53]. For this study, the Kriging model as well as the Matlab Kriging toolbox described in [54] were used.

The data obtained from the injection molding experiments, shown in Table 3, were used to generate the three relationships using the kriging Matlab toolbox. The three relationships have been plotted for the various process parameters, as shown in Figures 4-6, respectively.

These plots provide some insight into the relationships between the cycle time and the process parameters as well as the relationship between the two defects and the process parameters. For instance, in Figure 4(a), it can be seen that the cycle time increases with decreasing melt temperature. It is observed in Figures 4(b) and 4(d) that the cycle time increases with increasing cooling time and increasing packing time, respectively, which is an 


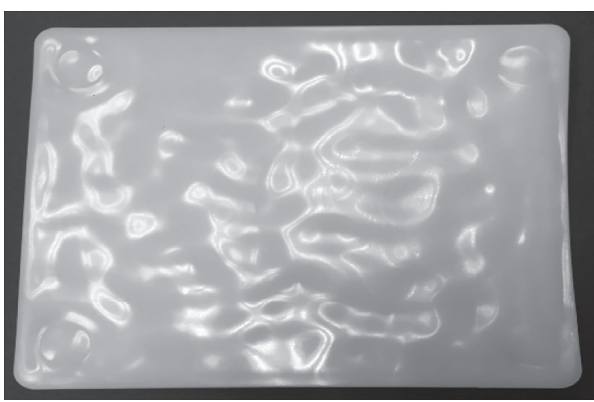

(a)

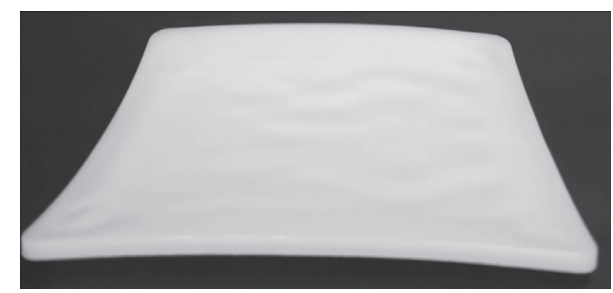

(b)

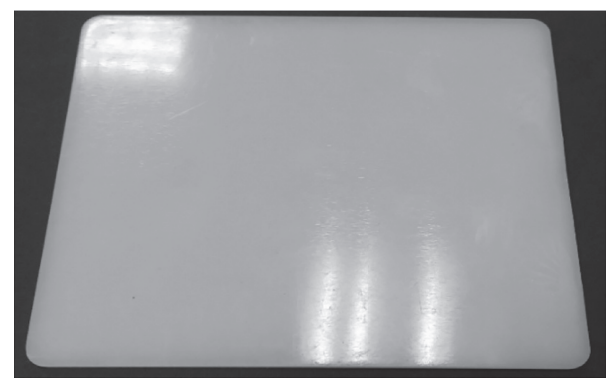

(c)

FIGURE 3: Products resulting from the injection molding experiments. (a) Product with severe volumetric shrinkage (warpage of 8.1 mm and volumetric shrinkage of $6.49 \mathrm{~mm}^{3}$ ), (b) product with severe warpage (warpage of $13.6 \mathrm{~mm}$ and volumetric shrinkage of $6.25 \mathrm{~mm}{ }^{3}$ ), and (c) acceptable product (warpage of $2.9 \mathrm{~mm}$ and volumetric shrinkage of $2.45 \mathrm{~mm}^{3}$ ).

TABLE 3: Experimental results for warpage, volumetric shrinkage, and cycle time.

\begin{tabular}{|c|c|c|c|c|c|c|c|c|c|c|c|}
\hline & $\begin{array}{c}\text { Injection } \\
\text { speed } \\
\mathrm{mm} / \mathrm{s} \\
I_{S}\end{array}$ & $\begin{array}{c}\text { Injection } \\
\text { pressure } \\
\text { bar } \\
I_{P}\end{array}$ & $\begin{array}{c}\text { Measured } \\
\text { injection } \\
\text { pressure } \\
\text { bar } \\
I_{P}\end{array}$ & $\begin{array}{c}\text { Cooling } \\
\text { time } \\
\text { sec } \\
C_{t}\end{array}$ & $\begin{array}{c}\text { Packing } \\
\text { pressure } \\
\text { bar } \\
P_{P}\end{array}$ & $\begin{array}{l}\text { Mold } \\
\text { temp. } \\
{ }^{\circ} \mathrm{C} \\
\mathrm{Mo}_{T}\end{array}$ & $\begin{array}{c}\text { Packing } \\
\text { time } \\
\text { sec } \\
P_{t}\end{array}$ & $\begin{array}{c}\text { Melt } \\
\text { temp. } \\
{ }^{\circ} \mathrm{C} \\
M_{T}\end{array}$ & $\begin{array}{c}\text { Warpage } \\
\text { mm } \\
W_{1}\end{array}$ & $\begin{array}{c}\text { Volumetric } \\
\text { shrinkage } \\
\mathrm{cm}^{3} \\
W_{2}\end{array}$ & $\begin{array}{l}\text { Cycle } \\
\text { time } \\
\text { sec } \\
\mathrm{Cyc}_{t}\end{array}$ \\
\hline 1 & 15 & 450 & 457 & 10 & 100 & 15 & 9 & 200 & 5.8 & 3.97 & 31.1 \\
\hline 2 & 15 & 450 & 457 & 30 & 100 & 15 & 3 & 200 & 6.8 & 5.17 & 43.9 \\
\hline 3 & 15 & 450 & 457 & 10 & 400 & 15 & 3 & 200 & 6 & 4.59 & 24.7 \\
\hline 4 & 15 & 450 & 457 & 30 & 400 & 15 & 9 & 200 & 2.9 & 2.45 & 49.8 \\
\hline 5 & 15 & 800 & 462 & 10 & 100 & 15 & 3 & 200 & 4.5 & 5.26 & 24.5 \\
\hline 6 & 15 & 800 & 461 & 30 & 100 & 15 & 9 & 200 & 3.4 & 3.95 & 49.8 \\
\hline 7 & 15 & 800 & 460 & 10 & 400 & 15 & 9 & 200 & 3.9 & 2.55 & 31.4 \\
\hline 8 & 15 & 800 & 461 & 30 & 400 & 15 & 3 & 200 & 6 & 4.49 & 43.8 \\
\hline 9 & 60 & 450 & 452 & 10 & 100 & 15 & 3 & 200 & 4.4 & 5.38 & 23.6 \\
\hline 10 & 60 & 450 & 452 & 30 & 100 & 15 & 9 & 200 & 3.7 & 4 & 48.9 \\
\hline 11 & 60 & 450 & 452 & 10 & 400 & 15 & 9 & 200 & 3.5 & 2.63 & 30.3 \\
\hline 12 & 60 & 450 & 452 & 30 & 400 & 15 & 3 & 200 & 7.7 & 4.62 & 42.7 \\
\hline 13 & 60 & 800 & 785 & 10 & 100 & 15 & 9 & 200 & 5.8 & 4.34 & 29.0 \\
\hline 14 & 60 & 800 & 783 & 30 & 100 & 15 & 3 & 200 & 9.1 & 5.21 & 41.9 \\
\hline 15 & 60 & 800 & 791 & 10 & 400 & 15 & 3 & 200 & 7 & 4.1 & 22.9 \\
\hline 16 & 60 & 800 & 787 & 30 & 400 & 15 & 9 & 200 & 2.9 & 1.97 & 47.9 \\
\hline 17 & 15 & 450 & 447 & 10 & 100 & 45 & 3 & 200 & 4.7 & 5.33 & 25.6 \\
\hline 18 & 15 & 450 & 445 & 30 & 100 & 45 & 9 & 200 & 9 & 4.05 & 49.9 \\
\hline 19 & 15 & 450 & 450 & 10 & 400 & 45 & 9 & 200 & 5.1 & 3.24 & 31.2 \\
\hline 20 & 15 & 450 & 447 & 30 & 400 & 45 & 3 & 200 & 6.8 & 5.09 & 43.8 \\
\hline 21 & 15 & 800 & 445 & 10 & 100 & 45 & 9 & 200 & 4 & 4.1 & 30.9 \\
\hline 22 & 15 & 800 & 446 & 30 & 100 & 45 & 3 & 200 & 7.9 & 5.55 & 48.8 \\
\hline 23 & 15 & 800 & 444 & 10 & 400 & 45 & 3 & 200 & 9.6 & 5.17 & 24.8 \\
\hline 24 & 15 & 800 & 446 & 30 & 400 & 45 & 9 & 200 & 4 & 3.15 & 49.8 \\
\hline 25 & 60 & 450 & 453 & 10 & 100 & 45 & 9 & 200 & 4.5 & 4.19 & 29.8 \\
\hline 26 & 60 & 450 & 452 & 30 & 100 & 45 & 3 & 200 & 7.2 & 5.68 & 42.7 \\
\hline
\end{tabular}


TABle 3: Continued.

\begin{tabular}{|c|c|c|c|c|c|c|c|c|c|c|c|}
\hline & $\begin{array}{l}\text { Injection } \\
\text { speed }\end{array}$ & $\begin{array}{l}\text { Injection } \\
\text { pressure }\end{array}$ & $\begin{array}{c}\text { Measured } \\
\text { injection } \\
\text { pressure }\end{array}$ & $\begin{array}{l}\text { Cooling } \\
\text { time }\end{array}$ & $\begin{array}{l}\text { Packing } \\
\text { pressure }\end{array}$ & $\begin{array}{l}\text { Mold } \\
\text { temp. }\end{array}$ & $\begin{array}{l}\text { Packing } \\
\text { time }\end{array}$ & $\begin{array}{l}\text { Melt } \\
\text { temp. }\end{array}$ & Warpage & $\begin{array}{l}\text { Volumetric } \\
\text { shrinkage }\end{array}$ & $\begin{array}{l}\text { Cycle } \\
\text { time }\end{array}$ \\
\hline & $\mathrm{mm} / \mathrm{s}$ & bar & bar & $\mathrm{sec}$ & bar & ${ }^{\circ} \mathrm{C}$ & $\mathrm{sec}$ & ${ }^{\circ} \mathrm{C}$ & $\mathrm{mm}$ & $\mathrm{cm}^{3}$ & $\mathrm{sec}$ \\
\hline & $I_{S}$ & $I_{P}$ & $I_{P}$ & $C_{t}$ & $P_{P}$ & $\mathrm{Mo}_{T}$ & $P_{t}$ & $M_{T}$ & $W_{1}$ & $W_{2}$ & $\mathrm{Cyc}_{t}$ \\
\hline 27 & 60 & 450 & 453 & 10 & 400 & 45 & 3 & 200 & 8.6 & 5.31 & 23.3 \\
\hline 28 & 60 & 450 & 453 & 30 & 400 & 45 & 9 & 200 & 4.5 & 3.25 & 48.7 \\
\hline 29 & 60 & 800 & 783 & 10 & 100 & 45 & 3 & 200 & 11 & 5.53 & 22.4 \\
\hline 30 & 60 & 800 & 779 & 30 & 100 & 45 & 9 & 200 & 3.8 & 4.14 & 47.9 \\
\hline 31 & 60 & 800 & 781 & 10 & 400 & 45 & 9 & 200 & 6 & 2.28 & 29.4 \\
\hline 32 & 60 & 800 & 780 & 30 & 400 & 45 & 3 & 200 & 7.9 & 4.27 & 41.9 \\
\hline 33 & 15 & 450 & 343 & 10 & 100 & 15 & 3 & 250 & 8.4 & 5.92 & 24.4 \\
\hline 34 & 15 & 450 & 342 & 30 & 100 & 15 & 9 & 250 & 5.2 & 3.85 & 49.7 \\
\hline 35 & 15 & 450 & 343 & 10 & 400 & 15 & 9 & 250 & 4.5 & 3.12 & 31.4 \\
\hline 36 & 15 & 450 & 344 & 30 & 400 & 15 & 3 & 250 & 8 & 5.35 & 43.7 \\
\hline 37 & 15 & 800 & 345 & 10 & 100 & 15 & 9 & 250 & 5 & 3.95 & 31.2 \\
\hline 38 & 15 & 800 & 345 & 30 & 100 & 15 & 3 & 250 & 7.6 & 5.85 & 43.7 \\
\hline 39 & 15 & 800 & 348 & 10 & 400 & 15 & 3 & 250 & 6.7 & 5.48 & 24.6 \\
\hline 40 & 15 & 800 & 349 & 30 & 400 & 15 & 9 & 250 & 6.4 & 3.02 & 49.7 \\
\hline 41 & 60 & 450 & 451 & 10 & 100 & 15 & 9 & 250 & 4.8 & 4.15 & 29.5 \\
\hline 42 & 60 & 450 & 451 & 30 & 100 & 15 & 3 & 250 & 6 & 6.06 & 42.1 \\
\hline 43 & 60 & 450 & 452 & 10 & 400 & 15 & 3 & 250 & 7.7 & 5.83 & 22.9 \\
\hline 44 & 60 & 450 & 452 & 30 & 400 & 15 & 9 & 250 & 5.2 & 3.2 & 48.1 \\
\hline 45 & 60 & 800 & 639 & 10 & 100 & 15 & 3 & 250 & 16 & 6.16 & 22.6 \\
\hline 46 & 60 & 800 & 639 & 30 & 100 & 15 & 9 & 250 & 7.1 & 4.07 & 47.8 \\
\hline 47 & 60 & 800 & 639 & 10 & 400 & 15 & 9 & 250 & 6 & 3.29 & 29.5 \\
\hline 48 & 60 & 800 & 642 & 30 & 400 & 15 & 3 & 250 & 9.1 & 5.48 & 41.9 \\
\hline 49 & 15 & 450 & 333 & 10 & 100 & 45 & 9 & 250 & 5.8 & 4.54 & 30.8 \\
\hline 50 & 15 & 450 & 334 & 30 & 100 & 45 & 3 & 250 & 7.9 & 6.21 & 43.8 \\
\hline 51 & 15 & 450 & 335 & 10 & 400 & 45 & 3 & 250 & 9.9 & 5.95 & 24.3 \\
\hline 52 & 15 & 450 & 338 & 30 & 400 & 45 & 9 & 250 & 8.4 & 3.84 & 49.8 \\
\hline 53 & 15 & 800 & 336 & 10 & 100 & 45 & 3 & 250 & 13.6 & 6.25 & 24.3 \\
\hline 54 & 15 & 800 & 338 & 30 & 100 & 45 & 9 & 250 & 8.8 & 4.43 & 49.7 \\
\hline 55 & 15 & 800 & 338 & 10 & 400 & 45 & 9 & 250 & 7 & 3.94 & 31.0 \\
\hline 56 & 15 & 800 & 337 & 30 & 400 & 45 & 3 & 250 & 8.6 & 5.87 & 43.9 \\
\hline 57 & 60 & 450 & 451 & 10 & 100 & 45 & 3 & 250 & 8.1 & 6.49 & 22.6 \\
\hline 58 & 60 & 450 & 452 & 30 & 100 & 45 & 9 & 250 & 7.6 & 4.63 & 48.2 \\
\hline 59 & 60 & 450 & 452 & 10 & 400 & 45 & 9 & 250 & 9.3 & 4.13 & 29.4 \\
\hline 60 & 60 & 450 & 452 & 30 & 400 & 45 & 3 & 250 & 8.3 & 6.11 & 42.2 \\
\hline 61 & 37.5 & 625 & 625 & 20 & 250 & 30 & 6 & 200 & 6.2 & 4.2 & 35.4 \\
\hline 62 & 37.5 & 625 & 511 & 20 & 250 & 30 & 6 & 250 & 8 & 4.84 & 35.3 \\
\hline 63 & 37.5 & 625 & 625 & 20 & 250 & 15 & 6 & 225 & 9 & 4.26 & 35.3 \\
\hline 64 & 37.5 & 625 & 625 & 20 & 250 & 45 & 6 & 225 & 3.6 & 4.87 & 35.4 \\
\hline 65 & 15 & 625 & 395 & 20 & 250 & 30 & 6 & 225 & 7.3 & 4.31 & 35.9 \\
\hline 66 & 60 & 625 & 628 & 20 & 250 & 30 & 6 & 225 & 7.6 & 4.51 & 35.0 \\
\hline 67 & 37.5 & 450 & 452 & 20 & 250 & 30 & 6 & 225 & 6.5 & 4.44 & 35.6 \\
\hline 68 & 37.5 & 800 & 580 & 20 & 250 & 30 & 6 & 225 & 7.6 & 4.45 & 35.3 \\
\hline 69 & 37.5 & 625 & 625 & 20 & 100 & 30 & 6 & 225 & 4.8 & 4.97 & 35.4 \\
\hline 70 & 37.5 & 625 & 625 & 20 & 400 & 30 & 6 & 225 & 7.5 & 4.27 & 35.4 \\
\hline 71 & 37.5 & 625 & 625 & 10 & 250 & 30 & 6 & 225 & 6.3 & 4.61 & 26.1 \\
\hline 72 & 37.5 & 625 & 625 & 30 & 250 & 30 & 6 & 225 & 5.7 & 4.5 & 45.4 \\
\hline 73 & 37.5 & 625 & 625 & 20 & 250 & 30 & 3 & 225 & 7.4 & 5.61 & 32.4 \\
\hline 74 & 37.5 & 625 & 625 & 20 & 250 & 30 & 9 & 225 & 5.6 & 3.63 & 38.3 \\
\hline 75 & 37.5 & 625 & 625 & 20 & 250 & 30 & 6 & 225 & 7.2 & 4.54 & 35.3 \\
\hline 76 & 60 & 800 & 800 & 10 & 100 & 45 & 9 & 250 & 7.65 & 4.31 & 28.2 \\
\hline 77 & 60 & 800 & 800 & 30 & 100 & 45 & 3 & 250 & 8.01 & 5.66 & 42.2 \\
\hline 78 & 60 & 800 & 800 & 10 & 400 & 45 & 3 & 250 & 11.2 & 4.53 & 21.9 \\
\hline 79 & 60 & 800 & 800 & 30 & 400 & 45 & 9 & 250 & 4.88 & 2.51 & 47.4 \\
\hline
\end{tabular}

expected behavior. In Figure 4(c) it is also observed that the cycle time increases with decreasing injection pressure.
The plots in Figure 5 reveal the behavior of the warpage as a function of the process parameters. In Figure 5(a), it is observed that the warpage increases with 


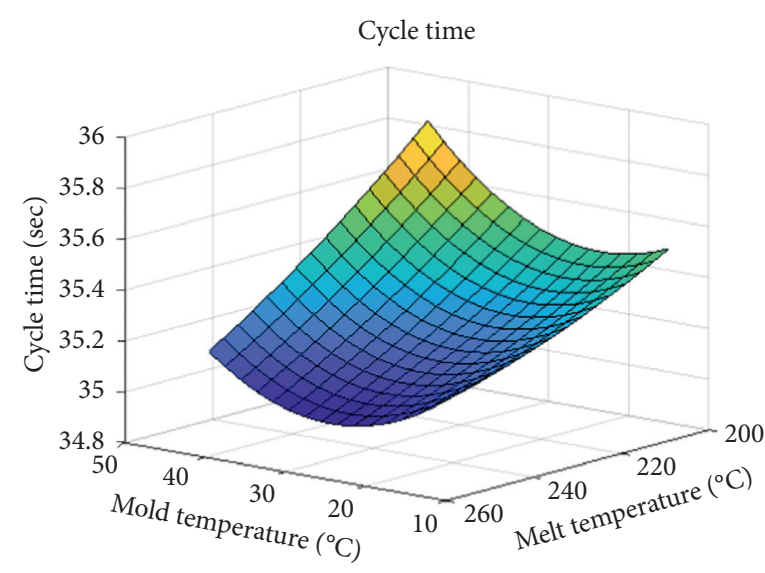

(a)

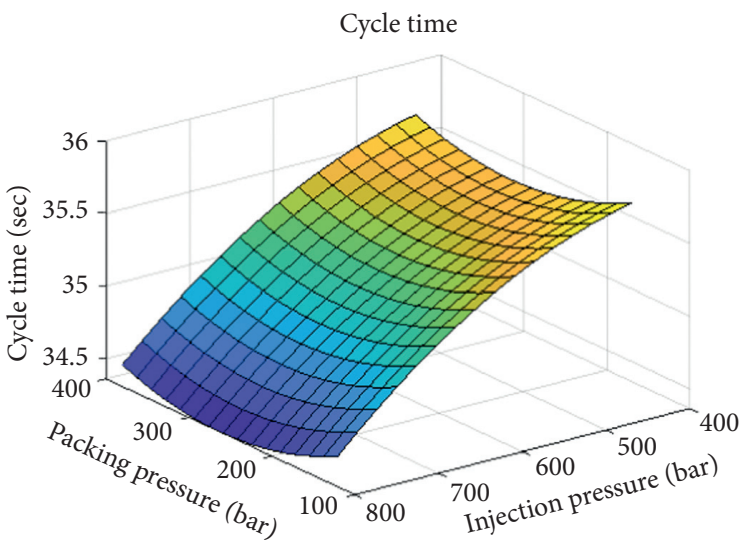

(c)

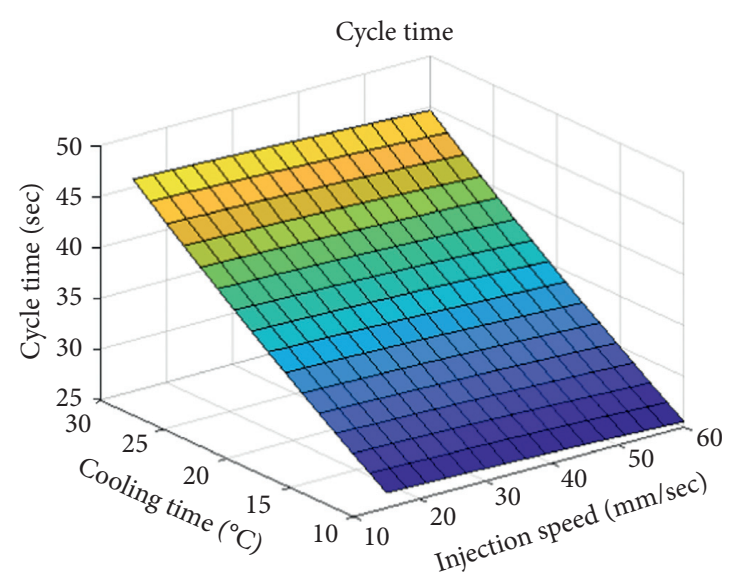

(b)

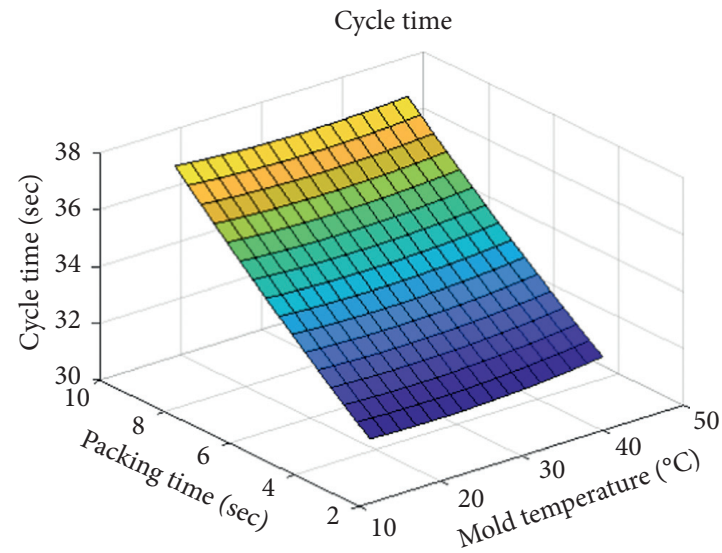

(d)

Figure 4: Plots showing the relation between cycle time and various process parameters. The plots are for cycle time versus (a) melt temperature and mold temperature, (b) cooling time and injection speed, (c) injection pressure and packing pressure, and (d) packing time and mold temperature.

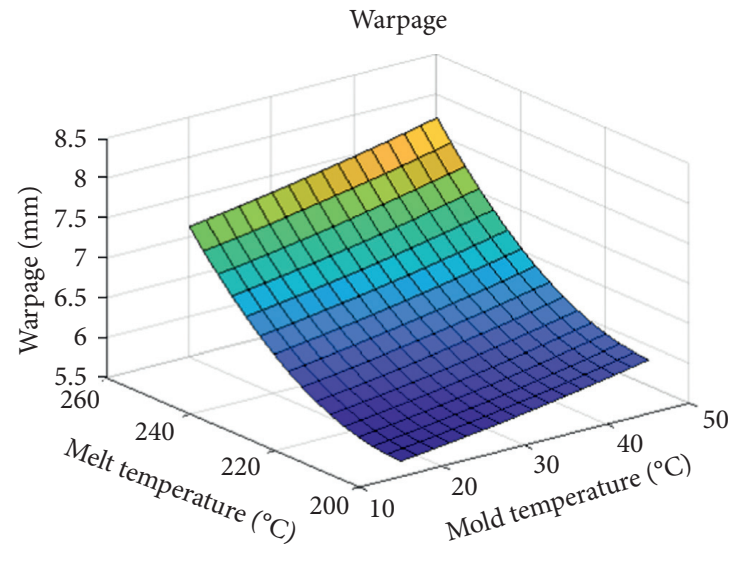

(a)

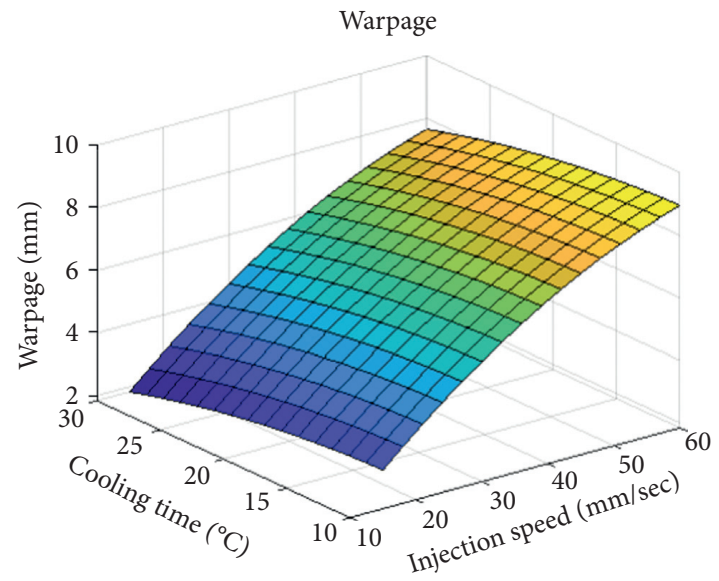

(b)

FIgURE 5: Continued. 


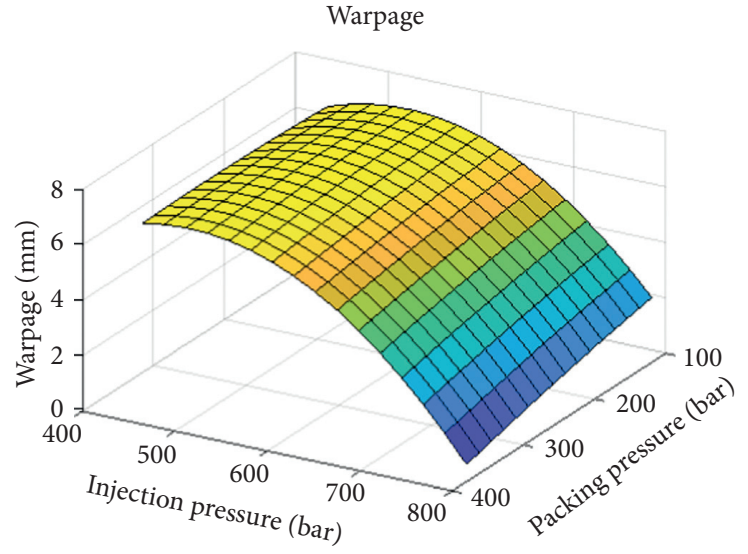

(c)

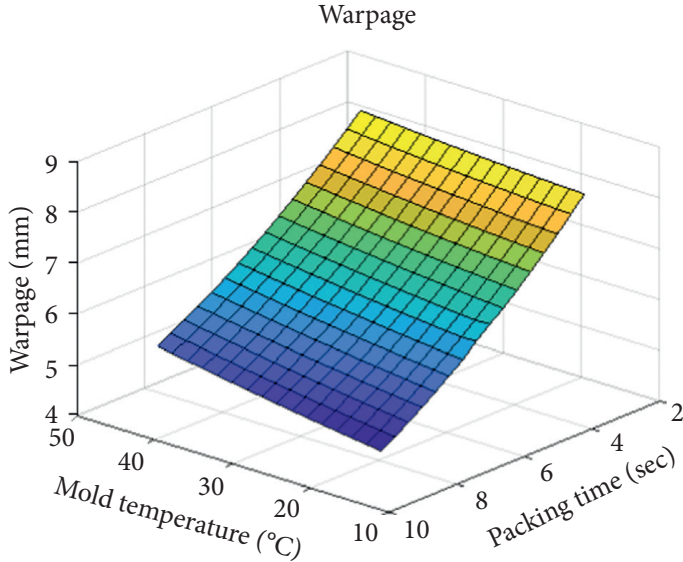

(d)

FIGURE 5: Plots showing the relation between warpage and various process parameters. The plots are for warpage verses (a) melt temperature and mold temperature, (b) cooling time and injection speed, (c) injection pressure and packing pressure, and (d) packing time and mold temperature.

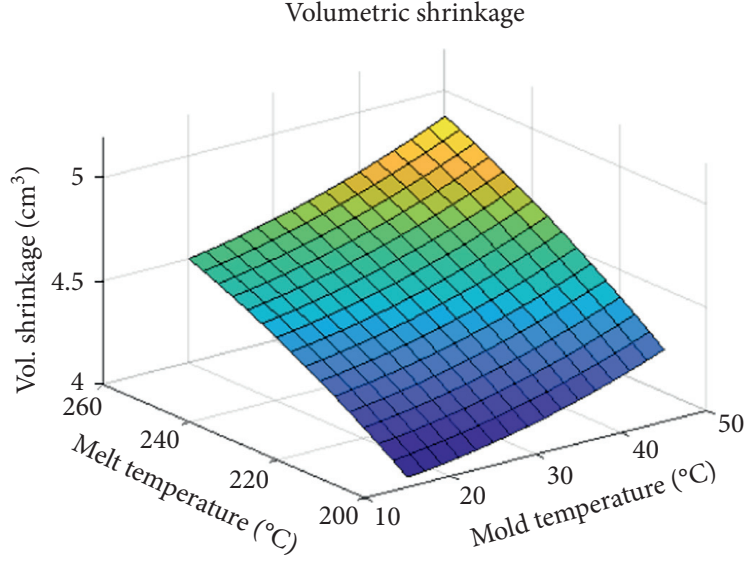

(a)

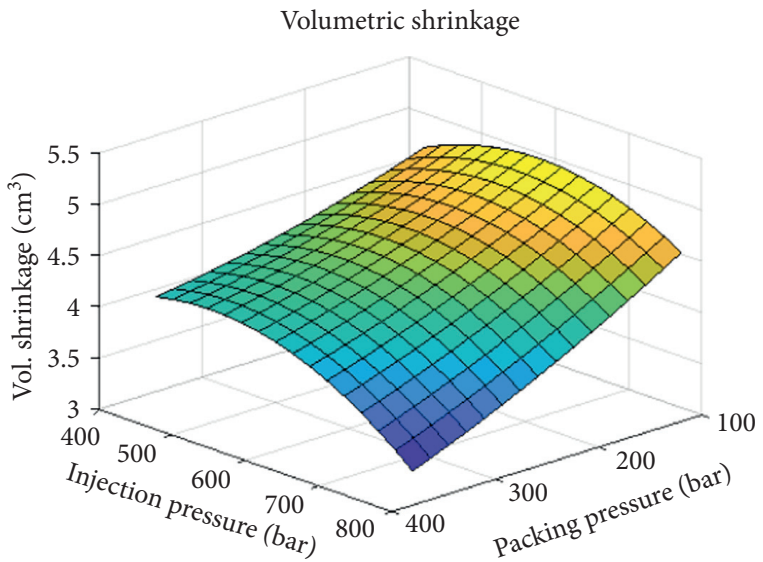

(c)

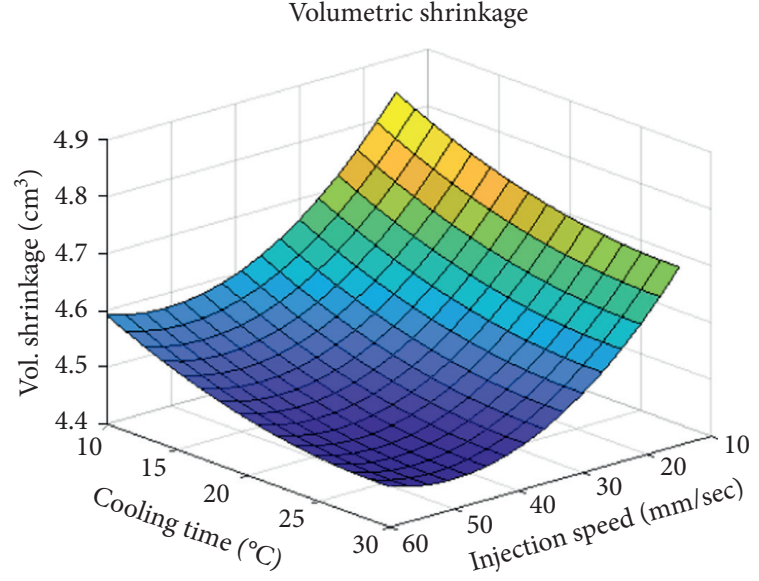

(b)

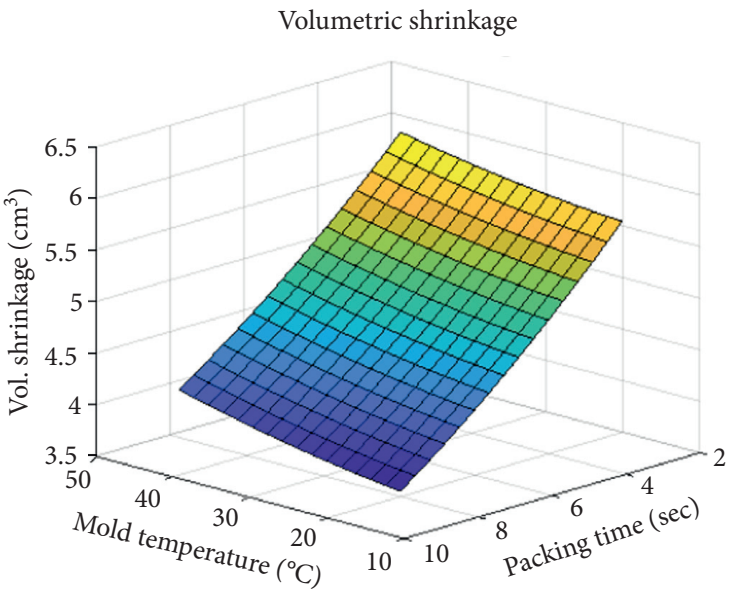

(d)

FIGURE 6: Plots showing the relation between volumetric shrinkage and various process parameters. The plots are for volumetric shrinkage versus (a) melt temperature and mold temperature, (b) cooling time and injection speed, (c) injection pressure and packing pressure, and (d) packing time and mold temperature. 
TABLE 4: Effect of process parameters on the on the product defect and the product cycle time.

\begin{tabular}{|c|c|c|c|}
\hline $\begin{array}{l}\text { Process } \\
\text { parameters }\end{array}$ & Warpage & $\begin{array}{l}\text { Volumetric } \\
\text { shrinkage }\end{array}$ & Comment \\
\hline Injection speed & \multirow{3}{*}{$\begin{array}{l}\text { Opposing } \\
\text { effect }\end{array}$} & \multirow{3}{*}{ Opposing effect } & $\begin{array}{c}\text { Reducing the injection speed decreases the warpage and vol. shrinkage but increases } \\
\text { the cycle time }\end{array}$ \\
\hline Cooling time & & & $\begin{array}{l}\text { Increasing the cooling time decreases the warpage and vol. shrinkage but increases } \\
\text { the cycle time }\end{array}$ \\
\hline Packing time & & & $\begin{array}{l}\text { Increasing the packing time decreases the warpage and vol. shrinkage but increases } \\
\text { the cycle time }\end{array}$ \\
\hline $\begin{array}{l}\text { Injection } \\
\text { pressure }\end{array}$ & \multirow{3}{*}{$\begin{array}{l}\text { Assisting } \\
\text { effect }\end{array}$} & \multirow{3}{*}{ Assisting effect } & $\begin{array}{l}\text { Increasing the injection pressure decreases the warpage and vol. shrinkage while } \\
\text { decreasing the cycle time }\end{array}$ \\
\hline $\begin{array}{l}\text { Mold } \\
\text { temperature }\end{array}$ & & & $\begin{array}{l}\text { Reducing the mold temperature decreases the warpage and vol. shrinkage and } \\
\text { decreases the cycle time }\end{array}$ \\
\hline $\begin{array}{l}\text { Melt } \\
\text { temperature }\end{array}$ & & & $\begin{array}{l}\text { Reducing the melt temperature decreases the warpage and vol. shrinkage and } \\
\text { decreases the cycle time }\end{array}$ \\
\hline $\begin{array}{l}\text { Packing } \\
\text { pressure }\end{array}$ & Not clear & Not clear & $\begin{array}{l}\text { Increasing the packing pressure decreases the warpage and vol. shrinkage; however, } \\
\text { from Figure } 4 c \text {, the effect on the cycle time is not clear }\end{array}$ \\
\hline
\end{tabular}

increasing melt temperature as well as increasing mold temperature (also observed in Figure 5(d)). From the plots in Figures 5(b)-5(d), it can be deduced that the warpage decreases with increasing cooling time, increasing injection pressure, increasing packing pressure, and increasing packing time.

The effects of the various process parameters on the volumetric shrinkage may be observed in the plots of Figure 6. It can be seen in Figure 6(a) that the volumetric shrinkage increases for an increase in both the melt temperature and mold temperature (also seen in Figure 6(d)). It can also be observed that the volumetric shrinkage increases for a decrease in the cooling time, decrease in the injection speed, a decrease in the injection pressure, a decrease in the packing pressure, and a decrease in the packing time.

Finally, from the plots in Figures 4-6, some important statements can be made regarding the effect of the process parameters on the product defect and the product cycle time. By observing Figures 4(b), 4(d), 5(b), 5(d), 6(b), and 6(d), it can be stated that the injection speed, the cooling time, and the packing time have the opposing effect of increasing the cycle time while reducing the product defects (or increasing the product defect while reducing the product cycle time). On the other hand, it can be inferred from Figures 4(a), 4(c), 5(a), 5(c), 6(a) and 6(c), that the injection pressure the mold temperature and the melt temperature have a supporting effect of lowering the product cycle time while lowering the product defect. These observations and inferences have been summarized in Table 4.

3.2. Parameter Optimization. The three relationships, previously developed, can be used to set up an optimization problem that can be solved in order to determine the best combination of process parameters that will lead to the minimum product cycle time while taking into account the product quality (or extent of product defect). The optimization problem can be expressed as
Table 5: Extreme values of the defect as reported in Table 3.

\begin{tabular}{lcc}
\hline & Lower extreme & Upper extreme \\
\hline$V_{\text {allowable }}$ & 1.97 & 6.49 \\
$W_{\text {allowable }}$ & 2.9 & 16 \\
\hline
\end{tabular}

$$
\begin{array}{ll}
\text { Minimize } & F=\mathrm{Cyc}_{t}\left(I_{S}, I_{P}, C_{t}, P_{P}, M o_{T}, P_{t}, M_{T}\right) \\
\text { Such that } & W_{\text {sum }}\left(I_{S}, I_{P}, C_{t}, P_{P}, M o_{T}, P_{t}, M_{T}\right) \leq W_{\text {allowable }} \\
& V_{\text {shrinkage }}\left(I_{S}, I_{P}, C_{t}, P_{P}, M o_{T}, P_{t}, M_{T}\right) \leq V_{\text {allowable }} \\
& 15 \leq I_{S} \leq 60 \mathrm{~mm} / \mathrm{s} \\
& 450 \leq I_{P} \leq 800 \mathrm{bar} \\
& 10 \leq C_{t} \leq 30 \mathrm{sec} \\
& 100 \leq P_{P} \leq 400 \mathrm{bar} \\
& 15 \leq M o_{T} \leq 45^{\circ} \mathrm{C} \\
& 3 \leq P_{t} \leq 9 \mathrm{sec} \\
& 200 \leq M_{T} \leq 250^{\circ} \mathrm{C} .
\end{array}
$$

In equation (4), $\mathrm{Cyc}_{t}$ is the cycle time to be minimized whereas, $I_{S}, I_{P}, C_{t}, P_{P}$, MOTP ${ }_{t}$, and $M_{T}$ refer to the injection speed, the injection pressure, the cooling time, the packing pressure, the mold temperature, the packing time, and the melt temperature, respectively. Also, in equation (4), $V_{\text {allowable }}$ and $W_{\text {allowable }}$ refer to the maximum allowable values of the volumetric shrinkage and warpage, respectively. They indicate the limits of the defect that may be considered acceptable on the product and should not be exceeded. To solve the optimization problem, it is sufficient to specify appropriate values for $V_{\text {allowable }}$ and $W_{\text {allowable. However, to gain an insight into the }}$ problem, a range of values between the lower and extreme values of the product defects (see Table 3) were specified for $V_{\text {allowable }}$ and $W_{\text {allowable. }}$ In particular, 100 sample points were selected in a grid-like fashion to cover the domain within the extremums. The extreme lower and upper defect values for the warpage and the volumetric shrinkage are listed, for convenience, in Table 5. 
TABLE 6: Extreme values of the defects maximum allowable values for the volumetric shrinkage and warpage with corresponding optimization results.

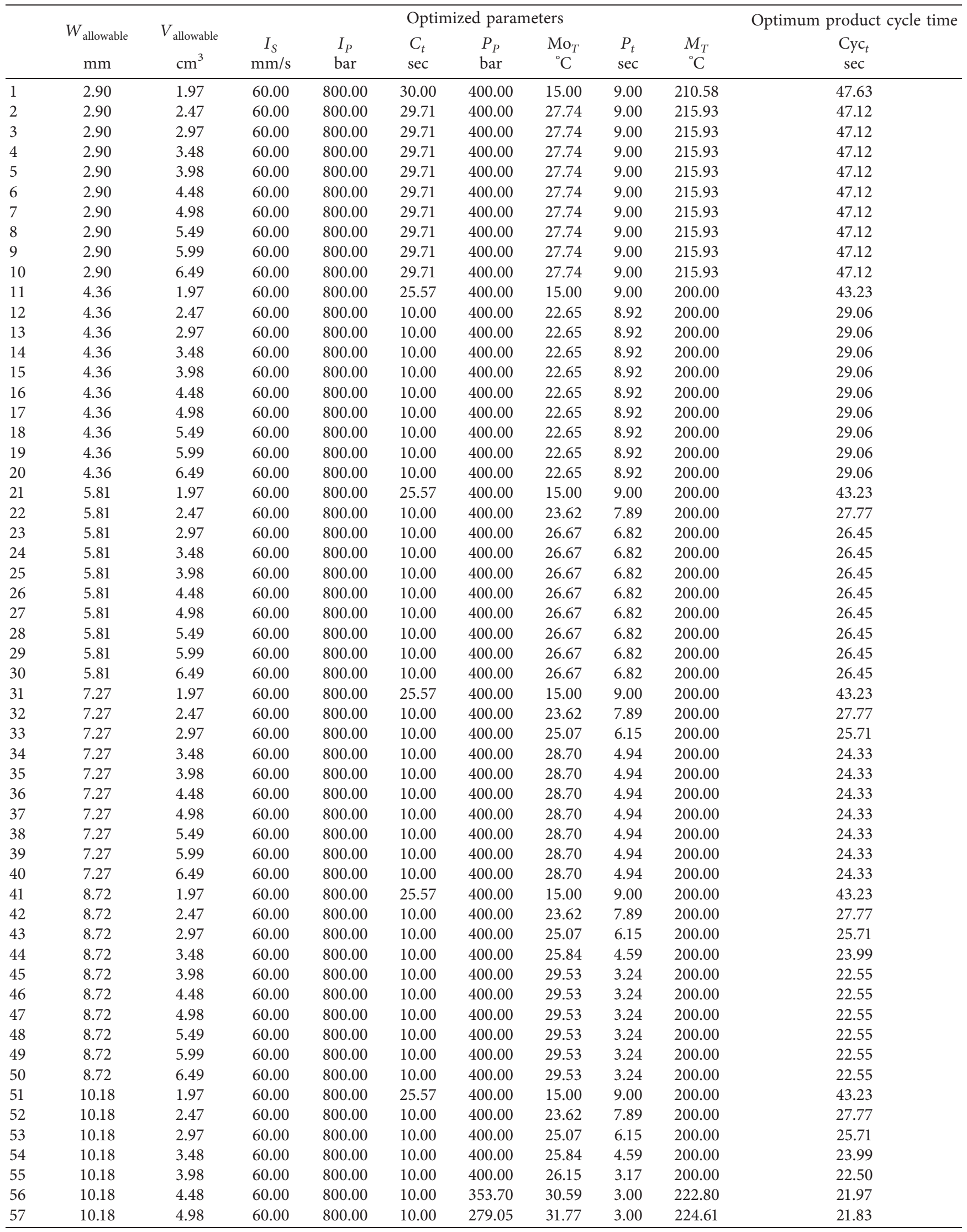


TABle 6: Continued.

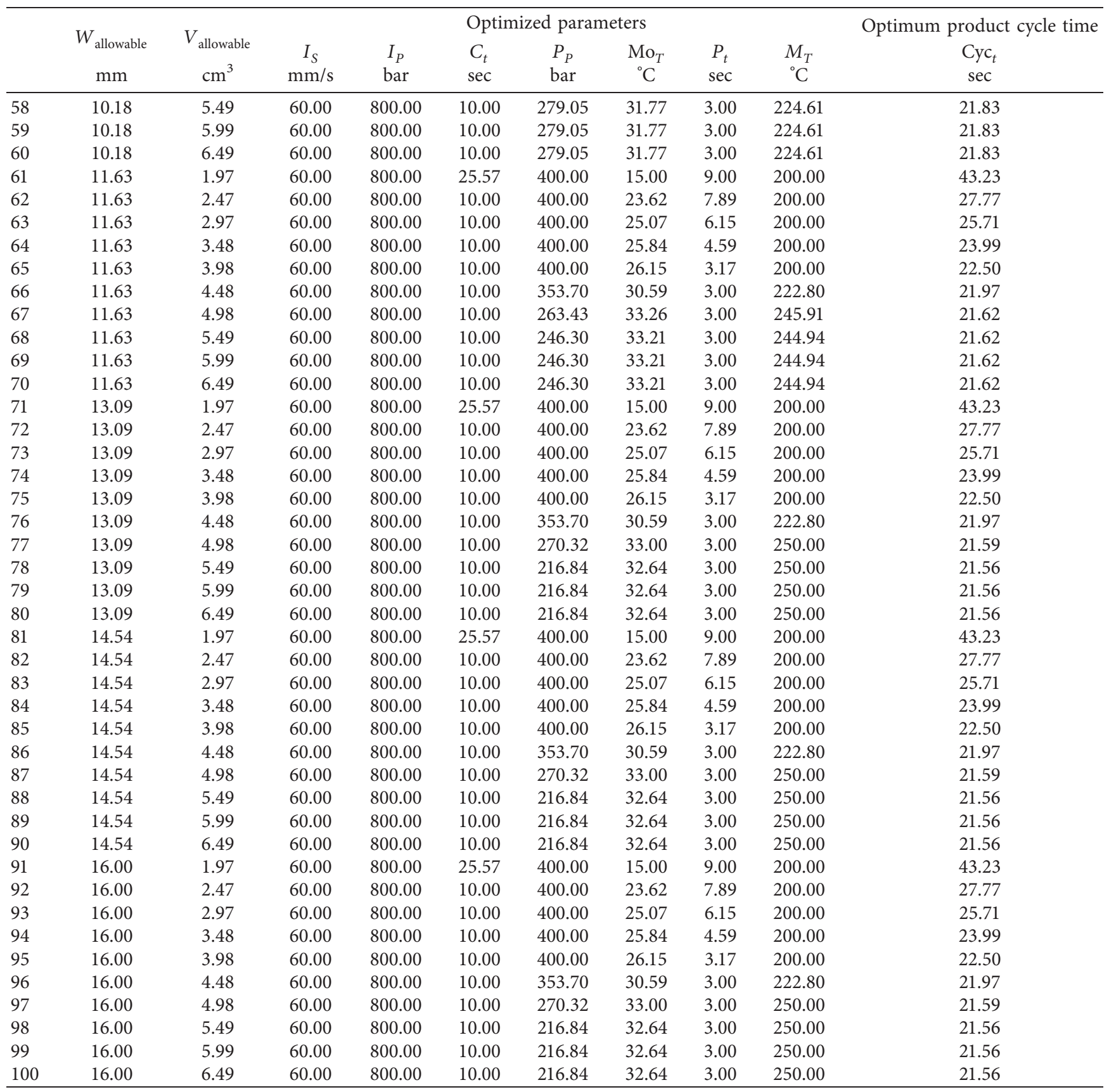

The optimization problem was solved (for each of the 100 sample points of $V_{\text {allowable }}$ and $W_{\text {allowable }}$ ) using the Fmincon function, available in the Matlab Optimization toolbox. The Fmincon function utilizes a sequential quadratic programming (SQP) algorithm which is an iterative technique used to solve nonlinearly constrained optimization problems. This technique has been found to be an effective tool when dealing with such problems, and further details of the Matlab function can be found in [55].

The optimization results are presented in Table 6 . The second and third columns in the table list the values of $W_{\text {allowable }}$ and $V_{\text {allowable }}$ whereas the remaining columns list the optimized parameters and the minimum product cycle time for the corresponding optimization. The results in Table 6 have also been plotted in Figure 7. The plot illustrates the competing objectives of lowering the cycle time and lowering the product defects. It can be seen from the plot that as the volumetric shrinkage constraint and warpage constraints are lowered, the optimized product cycle time increases. This behavior can be explained by previous observations as detailed in Table 4.

In order to assess the optimization process, an additional injection molding run was conducted with optimization results chosen randomly from Table 6. For this run, process parameters for sample 14 were used. The picture of the resulting product from this run is shown in Figure 8. Using equations (2) 


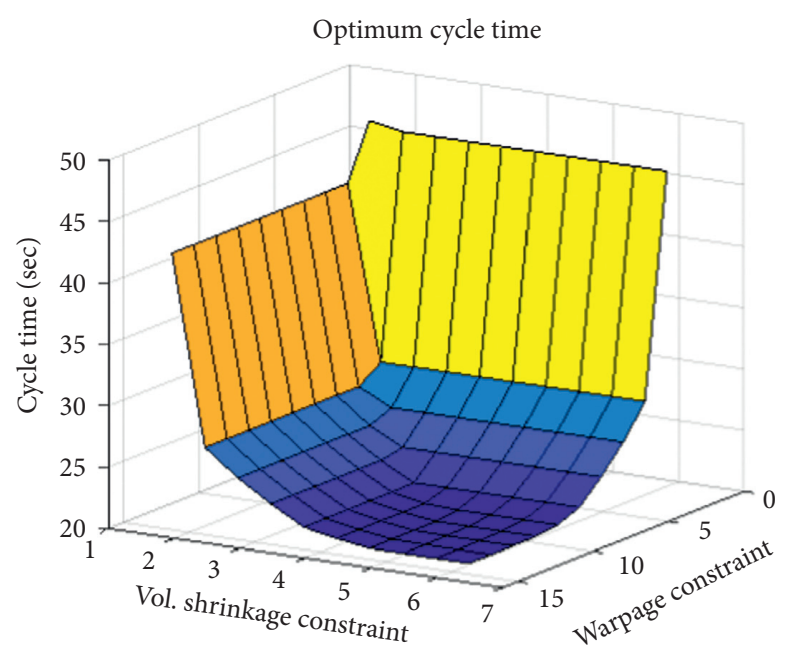

FIgURE 7: Optimization results showing optimum cycle times for a combination of the volumetric shrinkage and warpage constraints.

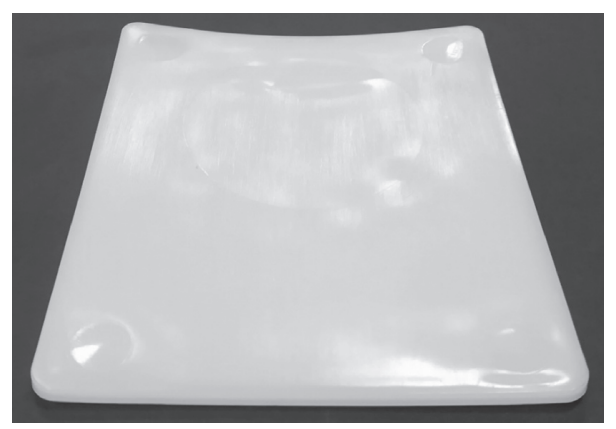

Figure 8: Picture of the optimization validation product (warpage constraint of 4.36 and volumetric shrinkage constraint of 3.48).

TABLE 7: Comparison of the optimization simulation results to the experimental validation results for the optimum cycle time, warpage, and volumetric shrinkage (the experimental validation was conducted based on the optimized process parameters, and the resulting cycle time, warpage, and volumetric shrinkage are compared to optimum simulation results, as shown in the table).

\begin{tabular}{|c|c|c|c|}
\hline & Optimized cycle time & Warpage & Vol. shrinkage \\
\hline Optimization results from the simulation (sample 14 in Table 6) & 29.06 & 4.36 & 3.48 \\
\hline Experimental validation results (inj. molding run for sample 14 parameters in Table 6) & 31.0 & 4.5 & 3.2 \\
\hline Difference & $6.7 \%$ & $3.2 \%$ & $8.0 \%$ \\
\hline
\end{tabular}

and (3), the warpage and the volumetric shrinkage were calculated for this product. The corresponding values are reported in Table 7. Also, in Table 7, the optimization validation experimental results are compared to the optimization results from the simulation. The comparison revealed reasonably close results with a difference in the cycle time, the warpage, and volumetric shrinkage by $6.7 \%, 3.2 \%$, and $8 \%$, respectively.

\section{Summary and Concluding Remarks}

The work in this study sought to develop an optimization framework for determining the minimum product cycle time while placing constraints on the product defect. The process involved developing three relationships relating the defects (warpage and volumetric shrinkage) and product cycle time, respectively, to seven process parameters (injection speed, injection pressure, cooling time, packing pressure, mold temperature, packing time, and melt temperature). The three relationships were developed based on data obtained through actual injection molding experiments. Surface plots of the three relationships revealed a number of important points. Firstly, that the cooling time and the packing time have the opposing effect of increasing the cycle time while reducing the product defects and secondly that the injection pressure, the mold temperature and the melt temperature have a supporting effect of lowering the product cycle time while lowering the product defect.

The relationship for the product cycle time was minimized subject to constraints on the product defects (described by the other two relationships). The optimization results illustrated competing objectives of lowering the cycle 
time against lowering the product defects. From the two previous observations, it may be concluded that the cooling time and the packing time are responsible for the competing objectives (i.e., in order to have a product with good quality we need to increase the cooling time and packing time which in turn increases the cycle time). On the other hand, the injection pressure, the mold temperature, and the melt temperature are factors that aid in achieving the two objectives.

As a means to validate the optimization process, an additional injection molding experiment was performed for one of the optimization results. The additional experimental results showed reasonably close agreement with the simulation optimization results differing in the cycle time, the warpage, and volumetric shrinkage by $6.7 \%, 3.2 \%$, and $8 \%$, respectively.

The optimization framework procedure outlined in this work was demonstrated using a simple product specimen and was able to achieve the intended outcome. There are, however, some important points that should be mentioned regarding the use of the procedure. Firstly, correct defect quantification is key to attaining credible results. Care should thus be taken in determining the required quantification. The product specimen used to demonstrate the procedure is a simple flat specimen whereas real-life products have more complex geometries and will require proper procedures for defect quantification. Secondly, the accuracy of the final results is dictated by how well the developed relationships are able to represent the product cycle time and product defects and how well the optimization routine is able to determine the optimum. It is thus important to compare those relationships to known trends to establish their accuracy before proceeding to the optimization stage. It is also recommended to perform validation tests, such as performed in this study, so as to have better confidence in the results.

The matter of cycle time reduction is an important issue in the injection molding industry. This is because reducing cycle time (even seconds) will lead to a substantial gain in production. However, reducing cycle time may have an adverse effect on product quality. The work in this study sought to find solutions to this matter. Based on the results from this work, it is the belief of the author that such an optimization framework can easy be adopted in the industry to aid the injection molding engineer as well as managers in making decisions on the appropriate process parameters that will result in acceptable product cycle times for acceptable product defect.

\section{Data Availability}

The experimental data used to support the findings of this study are included within the article.

\section{Conflicts of Interest}

The authors declare that they have no conflicts of interest.

\section{Acknowledgments}

The author acknowledges support from the Scientific Research Deanship at Qassim University as well as the technical support offered by the Higher Institute for Plastic Fabrication (HIPF) in Riyadh (Kingdom of Saudi Arabia).

\section{References}

[1] D. V. Rosato and M. G. Rosato, Injection Molding Handbook, Springer, New York, NY, USA, 3rd edition, 2000.

[2] M. Khan, S. K. Afaq, N. U. Khan, and S. Ahmad, "Cycle time reduction in injection molding process by selection of robust cooling channel design," ISRN Mechanical Engineering, vol. 2014, Article ID 968484, 8 pages, 2014.

[3] S. Kitayama, H. Miyakawa, M. Takano, and S. Aiba, "Multiobjective optimization of injection molding process parameters for short cycle time and warpage reduction using conformal cooling channel," The International Journal of Advanced Manufacturing Technology, vol. 88, no. 5-8, pp. 1735-1744, 2017.

[4] H.-S. Park and X.-P. Dang, "Development of a smart plastic injection mold with conformal cooling channels," Procedia Manufacturing, vol. 10, pp. 48-59, 2017.

[5] C. Fernandes, A. J. Pontes, and J. C. Viana, "Modeling and optimization of the injection-molding process: a review," Advances in Polymer Technology, vol. 37, no. 2, pp. 1-29, 2018.

[6] S. Kitayama, R. Ishizuki, M. Takano, Y. Kubo, and S. Aiba, "Optimization of mold temperature profile and process parameters for weld line reduction and short cycle time in rapid heat cycle molding," The International Journal of Advanced Manufacturing Technology, vol. 103, no. 5-8, pp. 1735-1744, 2019.

[7] Y. Wang, K.-M. Yu, and C. C. L. Wang, "Spiral and conformal cooling in plastic injection molding," Computer-Aided Design, vol. 63, pp. 1-11, 2015.

[8] E. Sachs, E. Wylonis, S. Allen, M. Cima, and H. Guo, "Production of injection molding tooling with conformal cooling channels using the three dimensional printing process," Polymer Engineering \& Science, vol. 40, no. 5, pp. 1232-1247, 2000.

[9] X. Xu, E. Sachs, and S. Allen, "The design of conformal cooling channels in injection molding tooling," Polymer Engineering \& Science, vol. 41, no. 7, pp. 1265-1279, 2001.

[10] D. E. Dimla, M. Camilotto, and F. Miani, "Design and optimisation of conformal cooling channels in injection moulding tools," Journal of Materials Processing Technology, vol. 164-165, no. 1, pp. 1294-1300, 2005.

[11] J. C. Ferreira and A. Mateus, "Studies of rapid soft tooling with conformal cooling channels for plastic injection moulding," Journal of Materials Processing Technology, vol. 142, no. 2, pp. 508-516, 2003.

[12] S. A. Jahan and H. El-Mounayri, "Optimal conformal cooling channels in 3D printed dies for plastic injection molding," Procedia Manufacturing, vol. 5, pp. 888-900, 2016.

[13] Z. Li, X. Wang, J. Gu et al., "Topology optimization for the design of conformal cooling system in thin-wall injection molding based on BEM," The International Journal of Advanced Manufacturing Technology, vol. 94, no. 1-4, pp. 1041-1059, 2018.

[14] S. Kitayama, Y. Yamazaki, M. Takano, and S. Aiba, "Numerical and experimental investigation of process parameters optimization in plastic injection molding using multi-criteria decision making," Simulation Modelling Practice and Theory, vol. 85, pp. 95-105, 2018.

[15] M. S. Shinde and K. M. Ashtankar, "Effect of different shapes of conformal cooling channel on the parameters of injection 
molding," Computers Materials \& Continua, vol. 54, no. 1, pp. 287-306, 2018.

[16] J. M. Mercado-Colmenero, C. Martin-Doñate, M. RodriguezSantiago, F. Moral-Pulido, and M. A. Rubio-Paramio, "A new conformal cooling lattice design procedure for injection molding applications based on expert algorithms," The International Journal of Advanced Manufacturing Technology, vol. 102, no. 5-8, pp. 1719-1746, 2019.

[17] H.-S. Park, X.-P. Dang, D.-S. Nguyen, and S. Kumar, "Design of advanced injection mold to increase cooling efficiency," International Journal of Precision Engineering and Manufacturing-Green Technology, vol. 7, no. 2, pp. 319-328, 2020.

[18] C.-C. Kuo, Y.-J. Zhu, Y.-Z. Wu, and Z.-Y. You, "Development and application of a large injection mold with conformal cooling channels," The International Journal of Advanced Manufacturing Technology, vol. 103, no. 1-4, pp. 689-701, 2019.

[19] K. W. Dalgarno, T. D. Stewart, and J. M. Allport, "Layer manufactured production tooling incorporating conformal heating channels for transfer moulding of elastomer compounds," Plastics, Rubber and Composites, vol. 30, no. 8, pp. 384-388, 2001.

[20] P. Zhao, H. Zhou, Y. Li, and D. Li, "Process parameters optimization of injection molding using a fast strip analysis as a surrogate model," The International Journal of Advanced Manufacturing Technology, vol. 49, no. 9-12, pp. 949-959, 2010.

[21] J. Cheng, Z. Liu, and J. Tan, "Multiobjective optimization of injection molding parameters based on soft computing and variable complexity method," The International Journal of Advanced Manufacturing Technology, vol. 66, no. 5-8, pp. 907-916, 2013.

[22] S. Kitayama, M. Yokoyama, M. Takano, and S. Aiba, "Multiobjective optimization of variable packing pressure profile and process parameters in plastic injection molding for minimizing warpage and cycle time," The International Journal of Advanced Manufacturing Technology, vol. 92, no. 9-12, pp. 3991-3999, 2017.

[23] A. Alvarado-Iniesta, O. Cuate, and O. Schütze, "Multi-objective and many objective design of plastic injection molding process," The International Journal of Advanced Manufacturing Technology, vol. 102, no. 9-12, pp. 3165-3180, 2019.

[24] C. Didaskalou, J. Kupai, L. Cseri et al., "Membrane-grafted asymmetric organocatalyst for an integrated synthesis-separation platform," ACS Catalysis, vol. 8, no. 8, pp. 7430-7438, 2018.

[25] M. Pettinato, A. A. Casazza, P. F. Ferrari, D. Palombo, and P. Perego, "Eco-sustainable recovery of antioxidants from spent coffee grounds by microwave-assisted extraction: process optimization, kinetic modeling and biological validation," Food and Bioproducts Processing, vol. 114, pp. 31-42, 2019.

[26] B. Cao, L. A. Adutwum, A. O. Oliynyk et al., "How to optimize materials and devices via design of experiments and machine learning: demonstration using organic photovoltaics," ACS Nano, vol. 12, no. 8, pp. 7434-7444, 2018.

[27] J. Möller, K. B. Kuchemüller, T. Steinmetz, K. S. Koopmann, and R. Pörtner, "Model-assisted design of experiments as a concept for knowledge-based bioprocess development," Bioprocess and Biosystems Engineering, vol. 42, no. 5, pp. 867-882, 2019.
[28] G. Székely, B. Henriques, M. Gil, and C. Alvarez, "Experimental design for the optimization and robustness testing of a liquid chromatography tandem mass spectrometry method for the trace analysis of the potentially genotoxic 1,3-diisopropylurea," Drug Testing and Analysis, vol. 6, no. 9, pp. 898-908, 2014.

[29] M. Eliasson, S. Rännar, R. Madsen et al., "Strategy for optimizing LC-MS data processing in metabolomics: a design of experiments approach," Analytical Chemistry, vol. 84, no. 15, pp. 6869-6876, 2012.

[30] W.-J. Deng, C.-T. Chen, C.-H. Sun, W.-C. Chen, and C.-P. Chen, "An effective approach for process parameter optimization in injection molding of plastic housing components," Polymer-Plastics Technology and Engineering, vol. 47, no. 9, pp. 910-919, 2008.

[31] G. Singh, M. K. Pradhan, and A. Verma, "Multi Response optimization of injection moulding Process parameters to reduce cycle time and warpage," in Proceedings of the International Conference on Emerging Trends in Materials and Manufacturing Engineering (IMME17), Tamil Nadu, India, March 2017.

[32] X.-P. Dang, "General frameworks for optimization of plastic injection molding process parameters," Simulation Modelling Practice and Theory, vol. 41, pp. 15-27, 2014.

[33] Y. Xu, Q. Zhang, W. Zhang, and P. Zhang, "Optimization of injection molding process parameters to improve the mechanical performance of polymer product against impact," The International Journal of Advanced Manufacturing Technology, vol. 76, no. 9-12, pp. 2199-2208, 2015.

[34] J. Zhao, G. Cheng, S. Ruan, and Z. Li, "Multi-objective optimization design of injection molding process parameters based on the improved efficient global optimization algorithm and non-dominated sorting-based genetic algorithm," The International Journal of Advanced Manufacturing Technology, vol. 78, no. 9-12, pp. 1813-1826, 2015.

[35] M. Mohan, M. N. M. Ansari, and R. A. Shanks, "Review on the effects of process parameters on strength, shrinkage, and warpage of injection molding plastic component," PolymerPlastics Technology and Engineering, vol. 56, no. 1, pp. 1-12, 2017.

[36] M. H. M. Hazwan, Z. Shayfull, S. Sharif, N. Zainal, and S. M. Nasir, "Optimisation of warpage on plastic injection moulding part with MGSS conformal cooling channels moulds using response surface methodology (RSM)," in Proceedings of the 2017 AIP Conference, Birmingham, UK, July 2017.

[37] Arburg. Allrounder 420 C Golden Edition, 2020, https://www. arburg.com/fileadmin/redaktion/Mediathek/Technische_Daten/ ARBURG_ALLROUNDER_420C_GOLDEN_EDITION_TD_ 523677_en_GB.pdf.

[38] SABIC. SABIC ${ }^{\circledR}$ HDPE M80064 High Density Polyethylene for Injection Moulding, 2020, http://www.b2bpolymers.com/ TDS/SABIC_M80064.pdf.

[39] G. W. A. Oehlert, First Course in Design and Analysis of Experiments, W. H. Freeman, New York, NY, USA, 2000.

[40] S. M. S. Mukras, H. M. Omar, and F. A. Al-Mufadi, "Experimental-based multi-objective optimization of injection molding process parameters," Arabian Journal for Science and Engineering, vol. 44, no. 9, pp. 7653-7665, 2019.

[41] G. H. Choi, K. D. Lee, and N. Chang, "Optimization of process parameters of injection molding with neural network application in a process simulation environment," CIRP Annals, vol. 43, no. 1, pp. 449-452, 1994. 
[42] B. Ozcelik and T. Erzurumlu, "Comparison of the warpage optimization in the plastic injection molding using ANOVA, neural network model and genetic algorithm," Journal of Materials Processing Technology, vol. 171, no. 3, pp. 437-445, 2006.

[43] C. Shen, L. Wang, and Q. Li, "Optimization of injection molding process parameters using combination of artificial neural network and genetic algorithm method," Journal of Materials Processing Technology, vol. 183, no. 2-3, pp. 412-418, 2007.

[44] F. Yin, H. Mao, and L. Hua, "A hybrid of back propagation neural network and genetic algorithm for optimization of injection molding process parameters," Materials \& Design, vol. 32, no. 6, pp. 3457-3464, 2011.

[45] M. Altan, "Reducing shrinkage in injection moldings via the Taguchi, ANOVA and neural network methods," Materials \& Design, vol. 31, no. 1, pp. 599-604, 2010.

[46] C.-Y. Shen, L.-X. Wang, and Q.-X. Zhang, "Process optimization of injection molding by the combining ANN/HGA method," Polymer Materials Science and Engineering, vol. 21, no. 5, pp. 23-27, 2005.

[47] H. Shi, Y. Gao, and X. Wang, "Optimization of injection molding process parameters using integrated artificial neural network model and expected improvement function method," The International Journal of Advanced Manufacturing Technology, vol. 48, no. 9-12, pp. 955-962, 2010.

[48] J. Zhou, L.-S. Turng, and A. Kramschuster, "Single and multi objective optimization for injection molding using numerical simulation with surrogate models and genetic algorithms," International Polymer Processing, vol. 21, no. 5, pp. 509-520, 2006.

[49] Y. Gao and X. Wang, "An effective warpage optimization method in injection molding based on the Kriging model," The International Journal of Advanced Manufacturing Technology, vol. 37, no. 9-10, pp. 953-960, 2008.

[50] H. Kurtaran and T. Erzurumlu, "Efficient warpage optimization of thin shell plastic parts using response surface methodology and genetic algorithm," The International Journal of Advanced Manufacturing Technology, vol. 27, no. 56, pp. 468-472, 2005.

[51] B. Ozcelik and T. Erzurumlu, "Determination of effecting dimensional parameters on warpage of thin shell plastic parts using integrated response surface method and genetic algorithm," International Communications in Heat and Mass Transfer, vol. 32, no. 8, pp. 1085-1094, 2005.

[52] C.-C. Chen, P.-L. Su, and Y.-C. Lin, "Analysis and modeling of effective parameters for dimension shrinkage variation of injection molded part with thin shell feature using response surface methodology," The International Journal of Advanced Manufacturing Technology, vol. 45, no. 11-12, pp. 1087-1095, 2009.

[53] J. D. Martin and T. W. Simpson, "Use of kriging models to approximate deterministic computer models," AIAA Journal, vol. 43, no. 4, pp. 853-863, 2005.

[54] S. N. Lophaven, H. B. Nielsen, and J. Søndergaard, "DACE-a matlab kriging toolbox," in IMM Informatics and Mathematical Modelling, pp. 1-34, Technical University of Denmark, Lyngby, Denmark, 2002.

[55] MathWorks. Constrained Nonlinear Optimization Algorithms, 2020, https:/www.mathworks.com/help/optim/ug/ constrained-nonlinear-optimization-algorithms.html. 